\title{
Implementation of a New Performance Management System - Driver for the Change of the Organisational Culture in a Telecommunication Company in the Middle East
}

\author{
Roxana Elisabeta HURDUBEI (IONESCU) ${ }^{1}$ \\ Alina Georgiana PROFIROIU ${ }^{2}$
}

\begin{abstract}
Many companies around the world consider the importance of the organisational culture for their success. Through this research, we aim to understand how the organisational culture can be changed by the implementation of new performance management system

This paper presents a case study where a consultancy company designed and implemented a performance management system for a large, multicultural telecommunication company in the Middle East. The article shows what were the approach and phases of the project, what was the impact on the initial cultural problems and also what were the success factors. Moreover, through this case study we could understand that companies can address and change the organisational culture by implementing performance management systems that is based not only on results or the outcomes produced, but also on the behaviours of their employees
\end{abstract}

Keywords: Organisation culture, behavioural competencies, performance management, organisational change, behavioural competencies

JEL classification: M1, M5

DOI: $10.24818 / \mathrm{RMCI} .2019 .1 .4$

\section{Introduction}

Business dictionary (2017) defines organisational culture as "The values and behaviours that contribute to the unique social and psychological environment of an organization" and Ticu Constantin (2008) considers that organisational culture is reflecting the "deep personality" of an organisation that is stabile in time and is conditioned by the long term vision and policy of that organisation.

Being the "deep personality" of a company, the organisational culture impact on many aspects of the HR processes e.g. Performance Management however, we observed that the relationship is bidirectional and there are cases when changing the HR processes can determine a change in the organisation culture itself.

1 Roxana Elisabeta Hurdubei (Ionescu), Bucharest University of Economic Studies, Romania

${ }^{2}$ Alina Georgiana Profiroiu, Bucharest University of Economic Studies, Romania, Email: alina_profiroiu@yahoo.com

$4 \quad$ Review of International Comparative Management $\quad$ Volume 20, Issue 1, March 2019 
The purpose of this research is to analyse how implementation of a performance management system impacts elements of organisational culture.

The methodology of this study consists in a case study for a large telecom company in Golf Cooperation Council (GCC). In this company, due to some characteristics of the organisation culture, most of the performance ratings were at the high end of the scale and this impacted on the possibility of identifying top performers and linking performance management results to annual bonus scheme.

To address this situation, the company developed a behavioural competency framework and implemented a new performance management system. Clear policies and procedures were communicated across the company along with objectives and behavioural standards for each job role. The performance management exercise conducted with the new system had a more balanced result of the ratings across the company that could be linked to the bonus scheme to reward top performers and motivate employees.

\section{Organisational Culture, Performance Management and Behavioural Competencies}

"Organizational culture represents a set of broad, tacitly understood rules which tell employees what to do under unanticipated work situations" (Camerer \& Vepsalainen, 1988). Therefore, culture affects members of an organization by influencing behavior and performance outcomes, including economic efficiency (Camerer and Vepsalainen, 1988)." (George, Sleeth, and Siders, 1999)

Lado and Wilson (1996) argue that by articulating a set of broad, tacit rules and values that serve to unify and regulate the behaviour and actions of organizational members, organizational culture may reduce the transaction costs entailed in the management of human resources. Barney and Zajac (1994) consider that "competencies (the strategically relevant behavioural and social phenomena inside a firm) are important issues in competitive organizational behaviour research."

"If an organization chooses the path of growth and excellence, then it needs to evaluate its performance. Looking more closely, the human capital in each organization is the key to growth and excellence." - (Anvari, Soltanib and Rafiee, 2016). Therefore, the employees should have competencies to fulfil the role requirements and achieve performance.

Aguinis and Pierce (2008) underline the stages of performance management as being "prerequisites, performance planning, performance execution, performance assessment, performance review, and performance renewal and re-contracting". Also, the author considers "performance management systems can be based on a consideration of behaviours (i.e., how work is completed), results (i.e., outcomes produced), or both."

Implementing behavioural guidelines in the human resources processes and implementing behavioural competency framework in performance 
management can determine a change in the organisational culture that can give a company competitive advantage. Moreover, Eden and Ackermann (2000) consider that "organisations with strategies based on core competencies are argued to survive recession better than others and to emerge stronger as economic recovery develops."

Scott and Einstein (2001) underline that "employee performance appraisal influences motivation and development, provides documentary support for rewards and recognition, and links the activities of individuals to organizational effectiveness. Appraisal of behaviour has possibly been the most used form over the last 30 or so years, and it involves identifying and rating observable behaviours relevant to individual work roles."

\section{Case Study}

This case study presents a Human Resources project that was conducted by a Human Resources Consultancy Company in Dubai for a leading telecommunications operator in the GCC (Gulf Cooperation Council) that since 1970 is serving consumers, enterprises, government and wholesale clients. In recent years, the company has been through a merger which resulted in re-branding and streamlining of internal processes. The company had a headcount of approximately 2600 employees and the first language is Arabic.

\subsection{Situation, Problem and Solution}

The company had a Performance Management system that included an annual appraisal. During the appraisal of their performance, most of the employees were rated at the high end of the scale. Therefore, Performance Management framework could not identify top performers and link performance management results to annual bonus scheme.

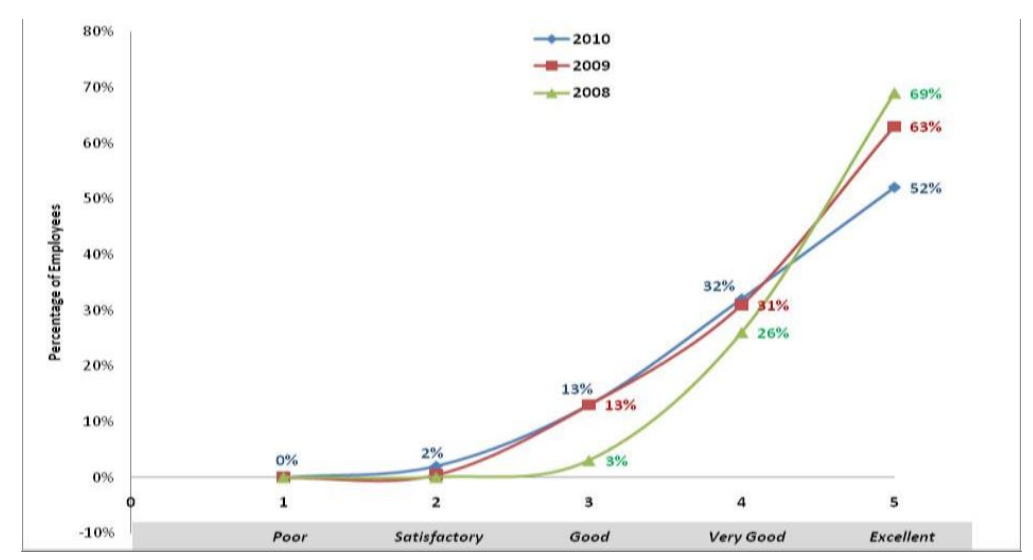

Chart 1: Performance Ratings Before Implementation of the Project

$6 \quad$ Review of International Comparative Management

Volume 20, Issue 1, March 2019 
To address this situation, a behavioural competency framework was developed, and a new performance management system was implemented. For this intervention and the result, the Human Resources Consultancy was awarded by CIPD (Chartered Institute of Personnel and Development) with the high commendation award.

\subsection{Approach}

The approach was structured as shown in the chart below in 3 main phases: data collection, analysis and recommendations.

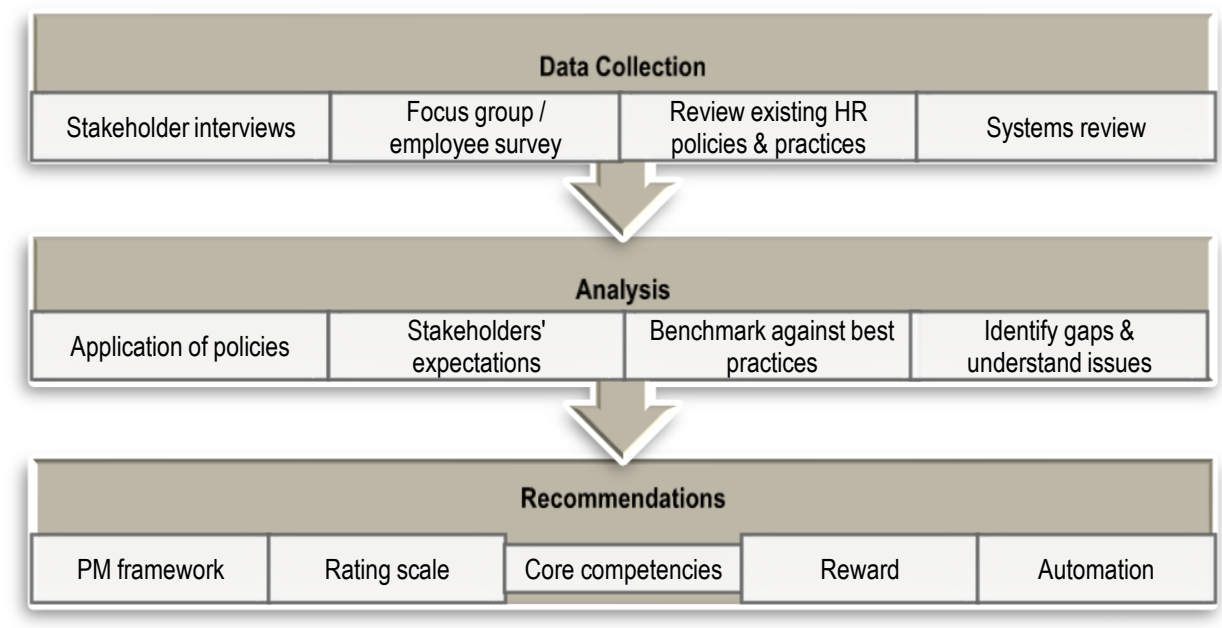

\section{Chart 2: Project Approach}

The data collection aimed to gather information to support the understanding of the specificities of the company, so the solution will be better focussed on addressing the needs. This phase included interviews with the stakeholders, an employee survey and a focus group and a system review. In this phase, the consultancy company also reviewed existing HR policies and practices.

The analysis phase was conducted to understand the degree to what the policies were implemented and what were the stakeholders' expectations. It also included a benchmarking exercise against the best practices to identify gaps and understand issues.

Following the analysis phase, several cultural particularities have been identified that may have impacted on the way ratings were given during the appraisal phase of the performance management cycle. The company had a multinational work environment and employees from diverse countries were working together. Friendliness, tolerance for other people's values and politeness are constantly encouraged and are an important part of the organisational culture. 
As a consequence, giving negative performance feedback is viewed as contradicting with politeness and tolerance and is challenging for many employees in the organisation.

Form this phase, other key findings were that there were previous unsuccessful attempts to solve this problem of having a normal distribution of performance ratings.

Performance management policy was not documented and employees were not clear what exactly was the process and what were their roles. The span of control reached 1:50 in some cases, managers having too many employees to conduct appraisal exercise for. Therefore, performance during the year was not documented and performance conversation did not take place in most of the cases. Objectives were not clearly set and were not formulated in the SMART format (specific, measurable, achievable, relevant, time limited).

Ratings and weightings were not clearly defined and behavioural competencies were not developed, mapped and included in the performance management framework. Managers and employees were not trained regarding performance management and therefore, the managers did have the capability to conduct performance appraisals and rate their direct reports appropriately for their performance during the year. Human resources employees themselves were not trained and were not clear about the requirements and phases of the performance management cycle. Moreover, the process was manual and required a great effort to input data from the forms into the system for being analysed.

The recommendations took into consideration all the findings from the previous phases and were formulated to address the problem. There were a total of 11 (eleven) recommendation:

1. Temporarily dissociate bonus from the performance management process (1-2 years). High performance ratings were also motivated by the managers not wanting to impact on their direct reports financial benefits. Cultural specificities were considered when this recommendation was formulated.

2. Introduce a new Performance Management framework and supporting policy. The framework should include behavioural competencies and objectives, should have a clear calendar and supporting policy properly disseminated.

3. Review span of control across the organisation to allow managers to manage performance of their direct reports and conduct performance conversations while documenting performance data.

4. Ensure objectives / KPIs are established to individual level and cascaded down from the department's objectives. Also, ensure objectives were formulated in the SMART format (specific, measurable, achievable, relevant, time limited)

5. Introduce a new performance rating scale that includes a description for each rating and that does have a neutral rating to avoid the middle tendency.

6. Introduce a Calibration process to ensure the normal distribution of the ratings across departments.

8 Review of International Comparative Management

Volume 20, Issue 1, March 2019 
7. Develop Individual Development Plans linked to outcome of appraisal. Bonuses were dissociated from the appraisal and the outcome of the performance management would be a personal development plat that would address development areas and will support career growth.

8. Communicate and train new framework across all levels. As part of the implementation, training sessions for employees were recommended to be conducted across all levels. Therefore, managers would know how to conduct performance discussions, rate and document performance of their direct reports and employees would understand what to expect from the process.

9. Automate Performance Management process. The company had the IT capacity to automate Performance Management process. Therefore, the performance management process would save time and resources for both the managers and the Human resources team.

10. Establish skilled Performance Management team in HR to ensure the Performance Management process runs smooth and all queries from managers or employees are solved efficiently.

11. Audit of Mid-Year reviews to ensure Performance Management Policy and Procedure are implemented correctly and all the activities are conducted as per the guidelines and in time.

\subsubsection{Phases of the project}

The project that considered all the recommendation had two phases: design of the solution and implementation.

\begin{tabular}{ll|}
\hline Design Phase & Implementation Phase \\
\hline Framework & Manager \& employee training \\
\hline Policy, forms \& templates & Systems implementation \\
\hline Core competencies & Audit of objectives \\
\hline Rating scale & Pilot of mid year review process \\
\hline Oracle customisation & Establish \& up-skill client team \\
\hline Communication plan & End year review \& calibration \\
\hline Training material & Post implementation review \\
\hline
\end{tabular}

Chart 3: Design and Implementation of the Project

Recommended performance framework included four main activities during the performance year: setting objectives, mid-year review, end of the year review and calibration and validation. 


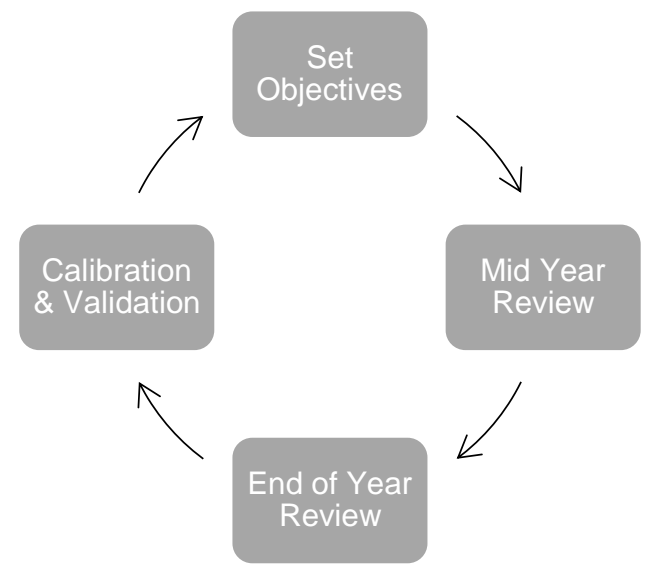

Chart 4: Recommended Performance Management Framework

The performance management system included appraisal of objectives and behavioural competencies. Therefore, a behavioural competency framework was developed. Core competencies were included in the job descriptions across the company and some behaviours related to performance management were included at the managerial level of "Result Orientation" competency.

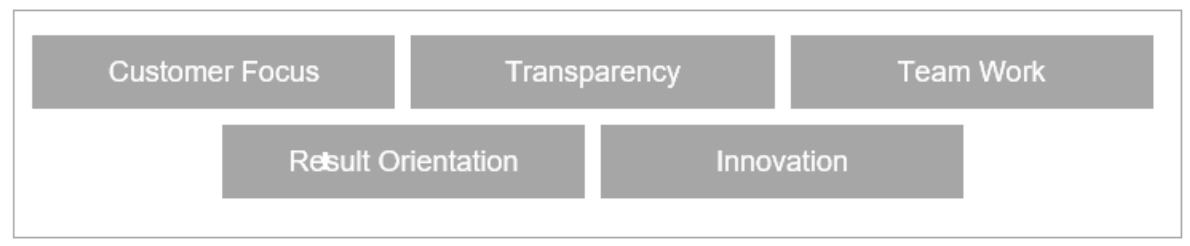

Chart 5: Core competencies included in the job descriptions

Behaviours included for managers level in "Result Orientation" competency:

- Drives motivation through reward and recognition in order to achieve high performance

- Sets smart objectives for team members to achieve results

- Regularly reviews and feeds back to team on results achieved

- Demonstrates commitment and implements Performance Management System

A four points rating scale was developed and included the descriptions of the rating.

$10 \quad$ Review of International Comparative Management

Volume 20, Issue 1, March 2019 
Performance Rating Scale

Table 1

\begin{tabular}{|c|c|}
\hline Rating & Description \\
\hline Outstanding & $\begin{array}{l}\text { Performance has significantly } \\
\text { expectations. The individual has made a significant } \\
\text { contribution to the organisation by exceeding the objectives } \\
\text { set and is seen as a role model in demonstrating behaviours. }\end{array}$ \\
\hline Well Achieved & $\begin{array}{l}\text { Performance fully meets expectations. The } \\
\text { individual has met their objectives fully and demonstrates the } \\
\text { desired behaviours. }\end{array}$ \\
\hline Almost Achieved & $\begin{array}{l}\text { Performance almost meets expectations. The } \\
\text { individual has made some contribution towards achieving } \\
\text { their objectives but has failed to achieve them in full. Does not } \\
\text { demonstrate all the desired behaviours. }\end{array}$ \\
\hline Unsatisfactory & $\begin{array}{l}\text { Performance is below expectations. The individual } \\
\text { has made no or a minimal contribution and failed to meet their } \\
\text { objectives. Does not desired behaviours. }\end{array}$ \\
\hline
\end{tabular}

\subsection{Impact of the project}

The project had a significant impact on the organisation and the results of the measures included:

- Policies and procedures provided clarity on Performance Management process and performance feedback method

- Managers were more willing to assess fairly the performance of their direct reports

- It was observed a dissociation between "politeness" and "performance feedback"

Performance ratings after implementation varied greatly from the previous ratings and the graph showed a normal distribution of the results.

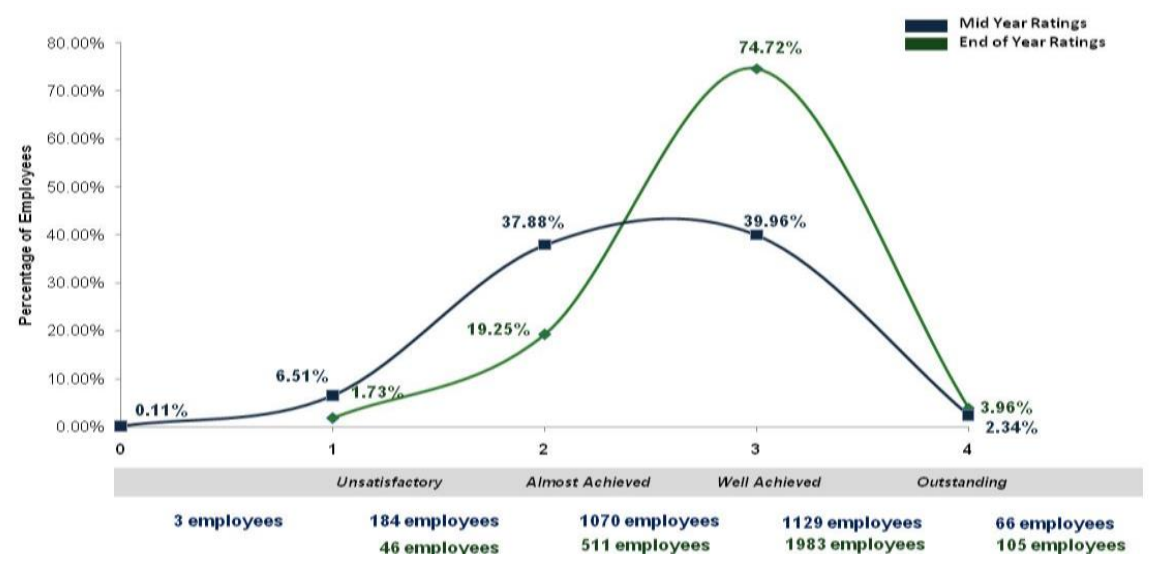

Chart 6: Performance Ratings after Implementation of the Project 
A Performance Management Survey was conducted for a sample of 217 employees after the completion of the first Performance Management cycle. After the analysis of the survey data, there were the following results:

- $67 \%$ of the employees answered their manager was fair and accurate in assessing their performance

- $65 \%$ of the employees answered their manager gives them feedback on performance and advise on how to improve regardless of performance rating

- From the appraisal process, $68.2 \%$ of the employees are clear about what they did well and where they need to improve

- $62 \%$ of the employees answered the appraisal process motivates the to do a good job

From the feedback provided by the consultancy company and the client organisation, one of the most important success factor for this project was the consideration for organisational and social culture that lead to understanding of the company politics (who's who and how things are done around here).

Other success factors identified included leadership support and buy-in and willingness to share responsibility. Hands on, solution-oriented approach, solutions that are simple and easy to implement, regular monitoring, reporting and follow up and flexibility and adaptability also came across as being very important.

\section{Conclusion}

Through this case study, we could draw the conclusion that implementation of performance management systems that is based on both objectives and behavioural competencies can have a significant impact on the organisational culture. Therefore, the environment was perceived by the employees as being more fair, the have more clarity regarding what is expected from them in their job and how they can improve. Also, the level of motivation increased.

Leadership support and commitment to the organisational change was one of the most important project's success factors. Also, the methodical implementation of simple and practical solutions that involved all the stakeholders and adapted to the needs of the company considering in the same time the best practices were crucial to the project.

\section{References}

Aguinis, H., \& Pierce, C. (2008). Enhancing the Relevance of Organizational Behavior by Embracing Performance Management Research. Journal of Organizational Behavior, 29(1), 139-145. Retrieved from http://www.jstor.org/stable/30162621

Anvari, A. F., Soltani I., Rafiee, M. (2016) - Providing the Applicable Model of Performance Management with Competencies Oriented, 3rd International 
Conference on New Challenges in Management and Organization: Organization and Leadership, Dubai, UAE, Procedia - Social and Behavioral Sciences 230, pp 190-197

Barney, J. B. and Zajac, E. J (1994) - Competitive Organizational Behavior: Toward an Organizationally-Based Theory of Competitive Advantage, Strategic Management Journal, Vol. 15, Special Issue: Competitive Organizational Behavior, pp. 5-9

Camerer, C. F. and Vepsalainen, A. (1988) - The Economic Efficiency of Corporate Culture, Strategic Management Journal, Vol. 9, Issue S1, June 1988, pp. $115-126$

Constantin, T. (2008) - Analiza climatului organizaţional. Psihologie organizațional managerială. Tendințe actuale (coord Avram E și Cooper C. L.), Editura Polirom Iași, pp 170-196

Eden, C and Ackermann, F. (2000) - Mapping Distinctive Competencies: A Systemic Approach, The Journal of the Operational Research Society, Vol. 51, No. 1, Part Special Issue: OR and Strategy, Published by: Palgrave Macmillan Journals on behalf of the Operational Research Society, pp. $12-20$

George, G., Sleeth, R. G. and Siders, M. A. (1999) - Organizing Culture: Leader Roles, Behaviors, and Reinforcement Mechanisms, Journal of Business and Psychology, Vol. 13, No. 4, Published by: Springer, pp. 545-560

Lado, A. A. and Wilson, M. C. (1994) - Human Resource Systems and Sustained Competitive Advantage: A Competency-Based Perspective, The Academy of Management Review, Vol. 19, No. 4, Published by: Academy of Management, pp. 699-727

Organizational culture. BusinessDictionary.com. Retrieved 2 October 2017, from BusinessDictionary.com website: http://www.businessdictionary.com/ definition/organizational-culture.html

Scott, S. G. and Einstein, W. O. (2001) - Strategic Performance Appraisal in TeamBased Organizations: One Size Does Not Fit All, The Academy of Management Executive (1993-2005), Vol. 15, No. 2, Theme: Positioning Organizations and People for Competitive Advantage, Published by: Academy of Management, pp. 107-116 